\title{
A Dispositional Approach to Examine the Impact towards Students Stressors in Indian Context
}

\section{Chandrasekar Therasa - Chidambaram Vijayabanu}

School of Management - SASTRA University - Thanjavur (India)

doi: 10.7358/ecps-2016-014-ther

samtheras@sastra.ac.in

vijayabanu@mba.sastra.edu

\section{UN APPROCCIO DISPOSIZIONALE PER ESAMINARE L'IMPATTO DEGLI STUDENTI VERSO LO STRESS NEL CONTESTO INDIANO}

\begin{abstract}
The current study explored the relationship between big five personality factors and various stressors of the students who are undergraduate, postgraduate and research scholars from nine colleges in North Chennai. The study is based on quantitative data with descriptive research design. The 20-item personality inventory developed by Donnellen et al. (2006) was used to analyse their personality and the stressors was measured using MSSQ (Medical Student Stressor Questionnaire) scale developed by Yusoff (2011). A total of 250 students were selected as respondents using cluster random sampling technique. It revealed a significant positive relationship with neuroticism and three types of stressors (academic, inter and intra personal and social). It also throws light on the personality trait, namely openness to experience played a major role in predicting the academic performance (CGPA). Through regression, it can be concluded that personality has a significant positive relationship with both academic and social stressors. The findings will provide appropriate measures for educators by realizing the importance of personality the student possesses and applying suitable strategies for them to improve their academic performance. The dispersal of the study's findings will significantly help students and the educators in the region.
\end{abstract}

Keywords: Academic performance, Big Five, Factor analysis, Regression, Stress, Student. 


\section{INTRODUCTION}

«Individuals often move away from home for the first time during this period and are cut off from family and friends who have provided significant social support in their lives» (Pancer et al., 2000). College students are more prone to stress, particularly freshmen (D'Zurilla \& Sheedy, 1991), because they must adjust themselves to the dynamic social environment, should maintain high academic performance. In addition to academic performance and requirements, cordial relations with the faculty members, increased workloads, time and financial pressures (Campbell \& Svenson, 1992), improper eating and sleeping habits (Wright, 1967) are considered as the prime cause of stress for the college students. Stress has become an important issue in academic circles. The consequences of stress have both positive and negative side if it is not properly managed (Stevenson \& Harper, 2006).

Although several studies confirmed that ability and achievement are the prime predictors of academic achievement, personality is considered as the strong predictor and it also has a consistent relationship with the academic success (O'Connor \& Paunonen, 2007). Various literature supports this view that personality is an important factor that influence academic motivation and achievement (Komarraju \& Karau, 2005). Therefore the present study aims to find out the effect of personality on various types of student stressors (academic, intra and inter personal and social stressors) and also its influence on academic performance. Human resource can be a dynamic asset or a debilitating liability depending upon how well it is harnessed. Dispositional based studies have gained renewed interest since performance is a mixture of perception and feelings (Therasa \& Vijayabanu, 2015). Personality is considered as one of the strongest predictors of individual well-being. To study the personality of individuals Big Five personality theory was adapted in this study, which includes five major factors namely (extraversion, agreeableness, conscientiousness, openness to experience and neuroticism). Stressors are external stimulus and personal events that are the root cause for stress. The sample of the current study includes the students community who belongs to Management and Arts \& Science. Stressors of sample students taken for the study include academic, inter and intra personal and social stressors.

\subsection{Big Five personality model}

The five factor model of personality is one of the flagship theory which fits in various personality traits into five well known traits, namely agreeableness, conscientiousness, neuroticism, openness to experience and extraversion. 
Agreeableness represents the tendency to be kind-natured, cooperative, and highly sensitive and trustworthy. A person who is high on agreeableness tends to interpersonally pleasing. A person who is high in conscientiousness tends to be dependable, responsible and ordered. Neuroticism is being highly emotional, which means unstable of managing their emotions. Openness to experience is being creative and imaginative, variety loving and independent. Extraversion is the person who is sociable and positive thinkers.

\subsection{Personality and the stressors}

Personality refers to individual difference which makes a person unique in the pattern of thought, feeling and behavior. There exist individual difference in how we react to stress, the coping style of individuals, the way they manage their stress, how they are responding to the stressors and the way they tackle the stressors (Lazarus, 1991). The study uses Big Five personality model since it is a general taxonomy, which includes various traits and are categorised into five classifications. Thus studying personality of students to identify the relationship between each type of stressors is a unique dimension and a vital study of the current educational system where younger generation (Gen $\mathrm{Y})$ is more prone to improper life style.

\subsection{Stressors and academic performance}

Academic performance was assessed by CGPA (Cumulative Grade Point Average), placements and Pay Scale. The dominant measure to find the academic performance is GPA according to Kuncel et al. (2005). There are also other stressors apart from the three stressors used for the current study, which includes Health related stressors - amount of exercise, sleeping habits and nutritional habits (Hammer et al., 1998). A study by Rafidah et al. (2009) examined the relationship between three stress factors (health, social and academic) and compared the level of the stress periodically at three different semester periods and its influence on academic performance and concluded that there exist some other factors which affect the academic performance of students. Thus the current study includes inter and intra personal stressors which plays a very role for the students to influence the academic performance. 


\section{Problem STATEMENT}

This study is provoked after reading a manuscript by Rafidah et al. (2009) on the impact of perceived stress towards academic performance by taking Prediploma science students in a university in Malaysia. The stressors included in the study are health, social and academic stressor during specified periods, namely beginning, middle and end of semester exams. The enormous amount of studies has dealt with various stressors and its impact on academic performance. The stress that normally students exposed includes family stress, emotional stress, financial stress and social stress. Especially the students who are doing their undergraduate programs will be exposed to stress greatly due to college life transition (Towbes \& Cohen, 1996). The stress may also cause psychological distress thereby, the students will lose their self-confidence and they might feel harder to cope up with the academic demands. Personality is a unique trait that every individual possess and it is having an intriguing relationship with the stressors also. Hence the current study explored the relationship between various personality traits and the stressors and its influence on the students' academic performance through their CGPA.

\subsection{Theoretical perspective}

According to Lazarus and Folkman (1984), stress is a «mental or physical phenomenon formed through one's cognitive appraisal of the stimulation and is a result of one's interaction with the environment». The existence of stress varies depends on the existence of the stressor. There are various stressors which cause stress among college students but for the current study the stressors included are academic stressors, inter and intra personal stressors and social stressors.

\subsection{Academic stressors}

Academic problems are considered to be the most common source of stress (Blumberg \& Flaherty, 1985; Clark \& Rieker, 1986; Evans \& Fitzgibbon, 1992). Schafer (1996) scrutinized the daily stressful situations of the college students and found that the school students are more prone to stress due to writing excessive term papers and projects, boring lectures and frequent class tests. Among the above said stressors, frequent test and exam is considered one of the important source of stress (Fisher, 1994). Getting low 
marks than they expect is also one of the stress causing source for the college students (Evans \& Fitzgibbon, 1992). Academic stressors has been linked to various negative outcomes such as deprived health issues (Greenberg, 1981), depressed states (Aldwin \& Greenberger, 1987) which leads to poor academic problems (Clark \& Rieker, 1986).

\subsection{Social factors}

The social factors considered for the current study includes lack of time for family and friends, concern towards family members, problems with the friends, frequent interruption in the work by others etc. The academic motivation or support rendered by the roommates or friends plays a vital role and have significant positive impact towards student's academic performance. There exists considerable number of studies on analyzing the impact of social support towards the academic performance of the students. Stress often crops up not only in the competitive and challenging work environment but also in monotonous and absence of people to stimulate the persons (Feng, 1992). A study which analyse the effects of homesickness among university students which includes mental and physical health problems, withdrawing behavior from schools, severe depression and it also focused on the prevention and remedial measures of how they can come out of it (Thurber \& Walton, 2012). The homesickness was associated to study the relationship with the dependent personality and place of attachment. The remedial measures prescribed self compassion as a protective factor to minimize the homesickness. In addition to the social factor, environmental factor also plays a very important role which affects students performance. A study which records the importance of spatial-physical features and its impact on stress reduction among pre-schoolers suggested that the physical environment of educational setting and positive social relations had direct impact on stress reduction (Carrus et al., 2012). They have also found that the relationship could also be moderated by educator's competencies through appropriate training.

\subsection{Inter and intra personal stressors}

Besides cultivating with knowledge, the students are indulged in socializing related activities with different kinds of people and undergo various psychological developments. A study by Sharma and Kaur (2011) analyzed the factors which induces stress for nursing students and concluded that

\footnotetext{
ECPS Journal - 14/2016

http://www.ledonline.it/ECPS-Journal/
} 
environmental factors had a contribution of $40 \%$ followed by interpersonal factors (30\%), and intrapersonal factors with 19\%. The interpersonal factors included in that study includes change in social activities, fight with close ones, lack of cooperation from friends, lack of close and intimate friends and conflict with the roommate. Another study by Pope (1982) examined the relationship between selected inter and intra personal factors and also the life management skills with the academic performance among secondary school students and concluded that there exists a strong positive correlation relationship between the variables taken for the study.

\section{RESEARCH OBJECTIVES AND HYPOTHESIS}

The purpose of this study is to identify the effect of personality and stressors on the academic performance of the students from various colleges at North Chennai. The basic hypothesis is that the performance level can be significantly lowered by the academic stressors and it is based on some personality traits. It is proposed that in addition to a variation in stressors, the variation in personality will also reduce the academic performance of the students. The study has the following objectives:

- To study the Big Five personality dimension (agreeableness, extraversion, openness, conscientiousness and neuroticism) influencing the academic performance of the students.

- To study the stressors (academic related stressor, intra and inter personal related stressor and social related stressor) affecting the performance of the students.

H1a. Personality traits and student stressors are correlated with each other. Students with higher academic stress will score high on tests of neuroticism.

H1b. Personality traits and CGPA are highly correlated with each other.

$\mathrm{H} 2$. The student stressors - academic, inter and intra personal and social stressors are random and are independent.

H3. There is an impact of the five factors of personality towards stressors among students and their CGPA. 


\section{Methodology}

\subsection{Participants}

The study's participants were 250 students from nine colleges of North Chennai. They were requested to participate in the survey, which comprise questions related to their personality and the stressors include academic related stressor, intra and inter personal related stressor and social related stressor. They were also requested to provide their demographic information like age and educational qualification. The mean age of the students was 21 years.

\subsection{Measures}

The 20-item personality inventory developed by Donnellen et al. (2006) was used to analyse their personality which covers five major facets namely extraversion, neuroticism, agreeableness, openness to experience and conscientiousness. Stressors was measured using MSSQ (Medical Student Stressor Questionnaire) scale developed by Yusoff (2011) and the current study used only three types of stressor namely academic stressor, intra and inter personal related stressor and social related stressor to assess stress among students in Chennai.

\section{RESULT AND DISCUSSIONS}

The Table 1 shows that $95.6 \%$ of student respondents of the current study are in the age group of $18-24$ years, $4.4 \%$ are in the age group of $25-34$ years. Hence it is interpreted that majority of the respondents are in the age group of $18-24$ years. The table also shows that $74.8 \%$ of the student respondents are under graduates, $14.8 \%$ of respondents are post graduates, and $10.4 \%$ of respondents are PhD scholars. Hence it is interpreted that majority of the sample student respondents are Under Graduates.

Research Question 1: What is the relationship between personality and various stressors (academic, intra and inter personal related and social) and also its relationship with the CGPA (academic performance)? 
Table 1. - Demographic details of students.

\begin{tabular}{|c|c|c|c|c|c|}
\hline $\begin{array}{c}\text { AgE } \\
\text { OF } \\
\text { STUDENTS }\end{array}$ & $\begin{array}{c}\text { NUMBER } \\
\text { OF } \\
\text { STUDENT } \\
\text { RESPONDENTS }\end{array}$ & Percent & $\begin{array}{c}\text { EDUCATIONAL } \\
\text { QUALIFICATION } \\
\text { OF } \\
\text { STUDENTS }\end{array}$ & $\begin{array}{c}\text { NuMBER } \\
\text { OF } \\
\text { STUDENT } \\
\text { RESPONDENTS }\end{array}$ & Percent \\
\hline $18-24$ & 239 & 95.6 & UG & 187 & 74.8 \\
\hline \multirow[t]{2}{*}{$25-34$} & 11 & 4.4 & PG & 37 & 14.8 \\
\hline & & & $\mathrm{PhD}$ & 26 & 10.4 \\
\hline TOTAL & 250 & 100 & & 250 & 100 \\
\hline
\end{tabular}

Source: Primary data.

\subsection{Correlation between personality types and stressors}

To answer the research Question 1, Hypothesis 1a and $1 \mathrm{~b}$ were formulated. To test the Hypothesis 1a formulated above, correlation analysis was conducted to study the relationship between the variables used for the study. From the Table 2, it can be inferred that there exists a statistically significant relationship between personality type and various stressor ranging from 0.104 to 0.478 . Among the personality traits, neuroticism has been the most influential, with statistically significant relationship with the stressors. The results revealed that students, who are highly neurotic (emotionally unstable), are more prone to stress ( $r=0.364$ for academic related stressor, $r=.308$ for inter and intra personal stressor and $r=.320$ for social stressor) and there exists a moderate score between agreeableness and social stressor $(r=.262)$. From the results of correlation analysis, it can be interestingly concluded that when students are emotionally unstable then their stress level will be much higher.

To examine the Hypothesis $1 \mathrm{~b}$, the inter relationship between students personality types and their academic performance through their CGPA (Cumulative Grade Point Average), was found out through correlation analysis and the results revealed that the students who are emotionally unstable are not able to get good score (CGPA), which means that their CGPA levels were very low $(r=-.255)$. On the other hand, students who are highly creative (openness to experience) tends to be good in their CGPA score $(r=.134)$. Out of five personality traits, openness to experience and neuroticism shows significant relationship with CGPA (academic performance) (Table 3).

Research Question 2: Which is the mostly considered stress to the students (academic, intra and inter personal related and social) based on their personality? 


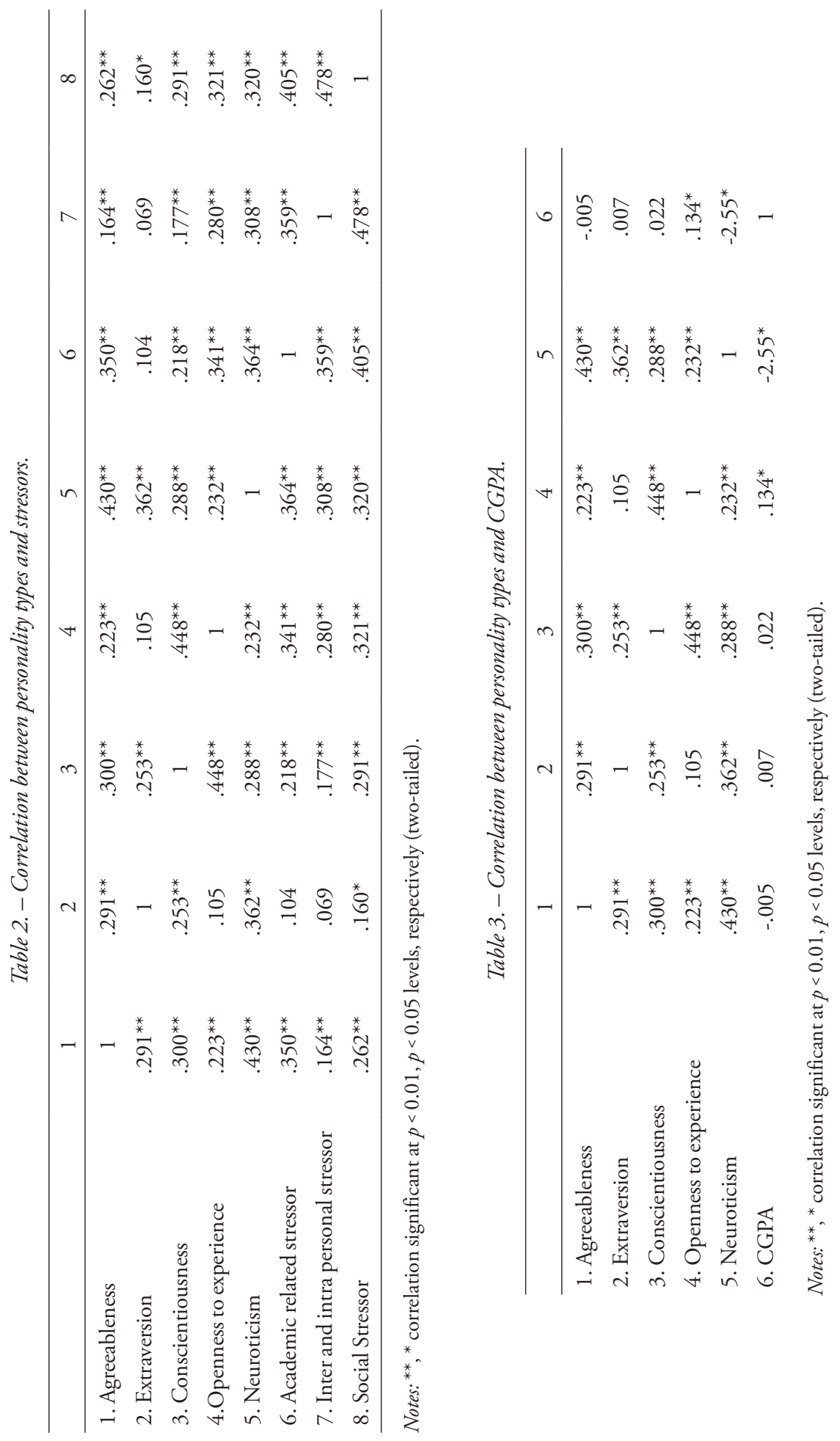


The research Question 2 was sorted out by testing the Hypothesis 2. Friedman Mean ranking method was used to rank different types of stressors students exhibit and it was shown in Table 4. From the table it was inferred that «Large amount of content to be learnt» has been ranked one, «Heavy workload» ranked second and "Lack of time to revise what have been learnt» has been ranked third in academic stressor. "Working with computer» has been ranked first in social stressors. "Talking to friends' network about personal problems» has been ranked second. Chi-square test has been calculated to understand whether the factors determining various stressors among students are related.

Hypothesis 2: The student stressors - academic, inter and intra personal and social stressors are random and are independent.

The Chi-square value (300.601, $p<.05$ and 96.817, $p<.05$ ) for academic and social stressors are found significant, and hence the null hypothesis is rejected and it was concluded that stressors are interrelated to one another. But for the interpersonal stressors of the students $(p$ value is $0.00<0.05)$ the null hypothesis is accepted and it is concluded that inter and intra personal stress factors are independent among the student group since its $p$ value is not significant $(p<0.05)$.

The Cronbach alpha is $(0.814)$ which is used to examine the reliability of the data collected regarding students stressors such as - academic, inter and intra personal and social stressors from the perception of the students personality. It also checks the random error which causes any inconsistency with factors creating stress to the students due to student personality. The study used a set of questionnaire based on the model developed by Yusoff (2011) in determining various stressors of the students based on the personality. The coefficient of alpha is higher than (0.8) and the data has excellent internal consistency and reliability.

Research Question 3: Which personality dimensions are significant predictors of students stressors?

In the current study, ANOVA and Linear regression model was carried out with personality traits such as agreeableness, extraversion, conscientiousness, openness to experience, neuroticism as independent variables to predict the significant personality type causing stress among students and shown in Table 5. In the table, $r$ value represents simple correlation. The correlation value indicates quite high degree of correlation between personality and academic stressor $(r=0.491)$ and social related stressor $(r=0.446)$.The relationship is good between personality and intra and inter personal related stressor $(r=$ $0.384)$. 
Table 4. - Ranking of student stressors based on Friedman's Test.

\begin{tabular}{|c|c|c|c|c|}
\hline Stressors & $\begin{array}{c}\text { Friedman Test } \\
\text { MEan }\end{array}$ & RANK & $\begin{array}{c}\text { CRONBACH’s } \\
\text { ALPHA } \\
\text { IF ITEM DELETED }\end{array}$ & \\
\hline & & mic stress & & \\
\hline Tests/Examinations & 5.29 & 6 & .804 & \multirow{9}{*}{$\begin{array}{l}\text { Chi-square: } 300.601 \\
\text { Asymp. Sig.: } 0.000\end{array}$} \\
\hline $\begin{array}{l}\text { Falling behind } \\
\text { in reading schedule }\end{array}$ & 4.98 & 7 & .805 & \\
\hline $\begin{array}{l}\text { Large amount } \\
\text { of content to be learnt }\end{array}$ & 6.29 & 1 & .797 & \\
\hline $\begin{array}{l}\text { Having difficulty } \\
\text { understanding } \\
\text { he context }\end{array}$ & 4.27 & 8 & .800 & \\
\hline Getting poor marks & 3.74 & 9 & .804 & \\
\hline Quota system in exams & 3.59 & 4 & .803 & \\
\hline $\begin{array}{l}\text { Lack of time to revise } \\
\text { what have been learnt }\end{array}$ & 5.60 & 3 & .802 & \\
\hline $\begin{array}{l}\text { Learning context-full } \\
\text { of tough competition }\end{array}$ & 5.46 & 5 & .829 & \\
\hline Heavy workload & 5.78 & 2 & .794 & \\
\hline
\end{tabular}

Intra and inter personal related stressor

Verbal or physical abusive by other student (s) / teacher(s) /

$\begin{array}{lll}1.51 & 1 & .801\end{array}$

other personnel(s)

Chi-square: .450

Asymp. Sig.: 0.503

Conflict with other

student(s) / teacher(s) /

1.49

2

.800

other personnel(s)

Social related stressors

Lack of time for family

and friends

3.64

4

.804

Unable to answer

questions from friends

5

.802

Talking to friends

network about personal

Chi-square: 96.817

problems

of the parents

3.90

Frequent interruption of my work by others 


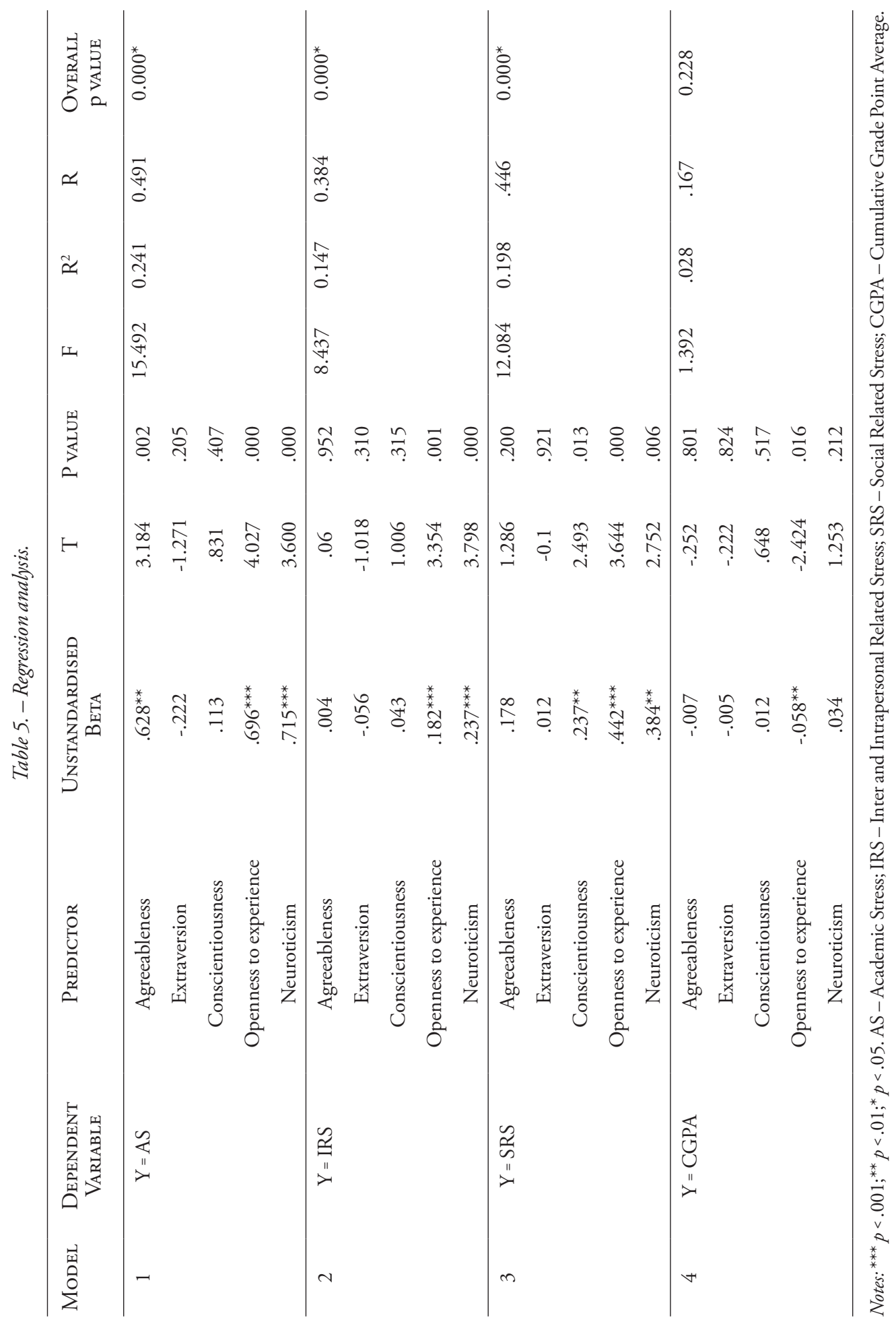


The $R^{2}$ column indicates how much of the total variation in the dependent variable (student stressors) can be explained by the independent variable (personality of the student) and here it is $24 \%$ can be explained by academic stressor, $19.8 \%$ by social related stressor and $14.7 \%$ by intra and inter personal related stressor which is quite good influence. Three of the personality factors conscientiousness, openness to experience, neuroticism towards student stressors have been explained in the model with much more statistical significance.

It is also inferred from the table the $F$ value is highest and significant for academic stressors (15.492) and social related stressors (12.084). So it is concluded that the regression model is statistically and significantly predicting the outcome of student stressors through personality factors which conclude a good fit for the data too.

Beta coefficients for the regression model provide necessary information to predict the level of student stress level from various types of student personality. In this part of the analysis regression model includes a testing of hypothesis. Five dimensions of Big Five personalities of the students were taken as independent variables against the stressors of the student as dependent variable in a multiple regression model. For all the hypotheses of the study mentioned above in the table hypothesis test was used at $95 \%$ confidence interval.

The hierarchical regression model 1 shows the regression coefficients of the five personality factors, out of which only three variables: agreeableness $(\beta=$ $.628 ; p<.002)$, openness to experience $(\beta=.696 ; p<.000)$ and neuroticism $(\beta=.715 ; p<.000)$ were statistically significant with the academic stressors.

The hierarchical regression model 2 shows the regression coefficients of the five personality factors, out of which only two variables: openness to experience $(\beta=.182 ; p<.001)$ and neuroticism $(\beta=.237 ; p<.000)$ were statistically significant with the inter and intra personal related stressors. The hierarchical regression model 3 shows the regression coefficients of the five personality factors, out of which only three variables: conscientiousness $(\beta=$ $.237 ; p<.013)$, openness to experience $(\beta=.442 ; p<.000)$ and neuroticism $(\beta=.384 ; p<.006)$ were statistically significant with the social related stressors. The hierarchical regression model 4 shows the regression coefficients of the five personality factors, out of which only one variable neuroticism $(\beta=$ $-.058 ; p<.016)$ was statistically significant with the CGPA.

Research Questions 4: What are the decisive stress factors of the student community that impinge on their academic performance?

Factor analysis has been used to reduce the seventeen key variables determining the stress level of the students into smaller number of factors and to identify decisive stress factors for the samples in the current study. It is vital

\footnotetext{
ECPS Journal - 14/2016

http://www.ledonline.it/ECPS-Journal/
} 
to decide the appropriateness of the data size before factor analysis. Both the Kaiser-Meyer-Olkin (KMO) measure of sampling adequacy and Bartlett's Test of Sphericity were used to check the adequacy of sample size. The values of KMO range between 0 and 1. According to Kaiser (1974), KMO values between 0.7 and 0.8 are good; values between 0.8 and 0.9 are great; and values above 0.9 are superb and the KMO results for the current study is shown in Table 6 .

Table 6. $-K M O$ and Bartlett's Test.

\begin{tabular}{lcc}
\hline KaISER-MEYer-OlKin MEASURe OF SAMPLing ADEQUACY & 0.821 \\
Bartlett's Test of Sphericity & Approx. Chi-square & 1012.617 \\
& Df & 105 \\
& Sig. & .000 \\
\hline
\end{tabular}

Principal component analysis provides a unique solution and the original data has been reconstructed from the results. The solution generated will prove the criteria for the retention of the variable. The Table 7 shows the communalities and Eigen values.

The listing of communalities for each item tells the variance accounted by each variable has been accounted for by the extracted factors. From the table $74.6 \%$ of the variance for "Lack of time for family and friends» is causing stress followed by $74.2 \%$ of the variance in "Inappropriate assignments» is accounted for while $71.5 \%$ of the variance in "Verbal or physical abusive by other student(s) / teacher(s) / other personnel(s)» is accounted for stressors affecting the student performance. Extraction communalities are estimates of the variance in each variable accounted for by the factors in the factor solution. Variance accounted by factors after rotation has been shown in Table 6.

The first six factors have Eigen values more than 1. Only these factors are rotated and cumulative \% refers to percent of variance accounted cumulatively by previous factor and this factor. The first six factors account for $63.184 \%$ of the variance, explain the general characteristics of the factors before and after rotation. Eigen value, also called as "characteristic roots" is the ratio of the explanatory importance of the factors with respect to the variables. If the factor has a low Eigen value, then it is contributing little to the explanation of variances and may be ignored as unnecessary. In other words, the amount of variance in each variable that can be explained by the retained factors is represented by the communalities after extraction (Field, 2005). 
Table 7. - Communalities and Eigen values.

\begin{tabular}{lccc}
\hline \multicolumn{4}{c}{ CoMmUNALITIES } \\
\hline & Extraction & Variance $\%$ & Cumulative \% \\
\hline Falling behind in reading schedule & .547 & 27.697 & 27.697 \\
Large amount of content to be learnt & .647 & 9.665 & 37.361 \\
Getting poor marks & .495 & 8.399 & 45.760 \\
Lack of time to revise what have been learnt & .587 & 6.825 & 52.586 \\
Heavy workload & .536 & 5.501 & 58.086 \\
Verbal or physical abusive by other & .715 & 5.097 & 63.184 \\
student(s) / teacher(s) / other personnel(s) & & & \\
Conflict with other student(s) / teacher(s) / & .705 & 4.277 & 67.460 \\
other personnel(s) & & & \\
Parental wish for you to study & .688 & 3.730 & 71.190 \\
Family responsibilities & .544 & 3.662 & 74.852 \\
Conflicts with other students & .534 & 3.431 & 78.283 \\
poor motivation to learn & .621 & 2.940 & 81.223 \\
Inexperienced teachers & .698 & 2.636 & 83.859 \\
Poor study material & .711 & 2.471 & 86.330 \\
Inappropriate assignments & .742 & 2.217 & 88.547 \\
Lack of recognition for work done & .706 & 2.121 & 90.668 \\
Unclear goals & .641 & 1.959 & 92.627 \\
Lack of time for family and friends & .746 & 1.875 & 94.502 \\
Unable to answer questions from friends & .679 & 1.578 & 96.081 \\
Facing illness or death of the parents & .536 & 1.470 & 97.551 \\
Frequent interruption of my work by others & .611 & 1.305 & 98.856 \\
Feeling of incompetence & .580 & 1.144 & 100.000 \\
\hline & & & \\
\hline
\end{tabular}

The Table 8 shows the factor loadings of the 21 variables on the six factors extracted. The higher the absolute value of the loading, the more the factor contributes to the variable. All loadings less than 0.5 have been suppressed and four factors namely (i) Academic stress; (ii) Lack of resource; (iii) Interpersonal stress; (iv) Social stress; (v) Intrapersonal stress; (vi) Family stress emerged as the major factor to determine students stressors based on their personality for their better academic performance. 


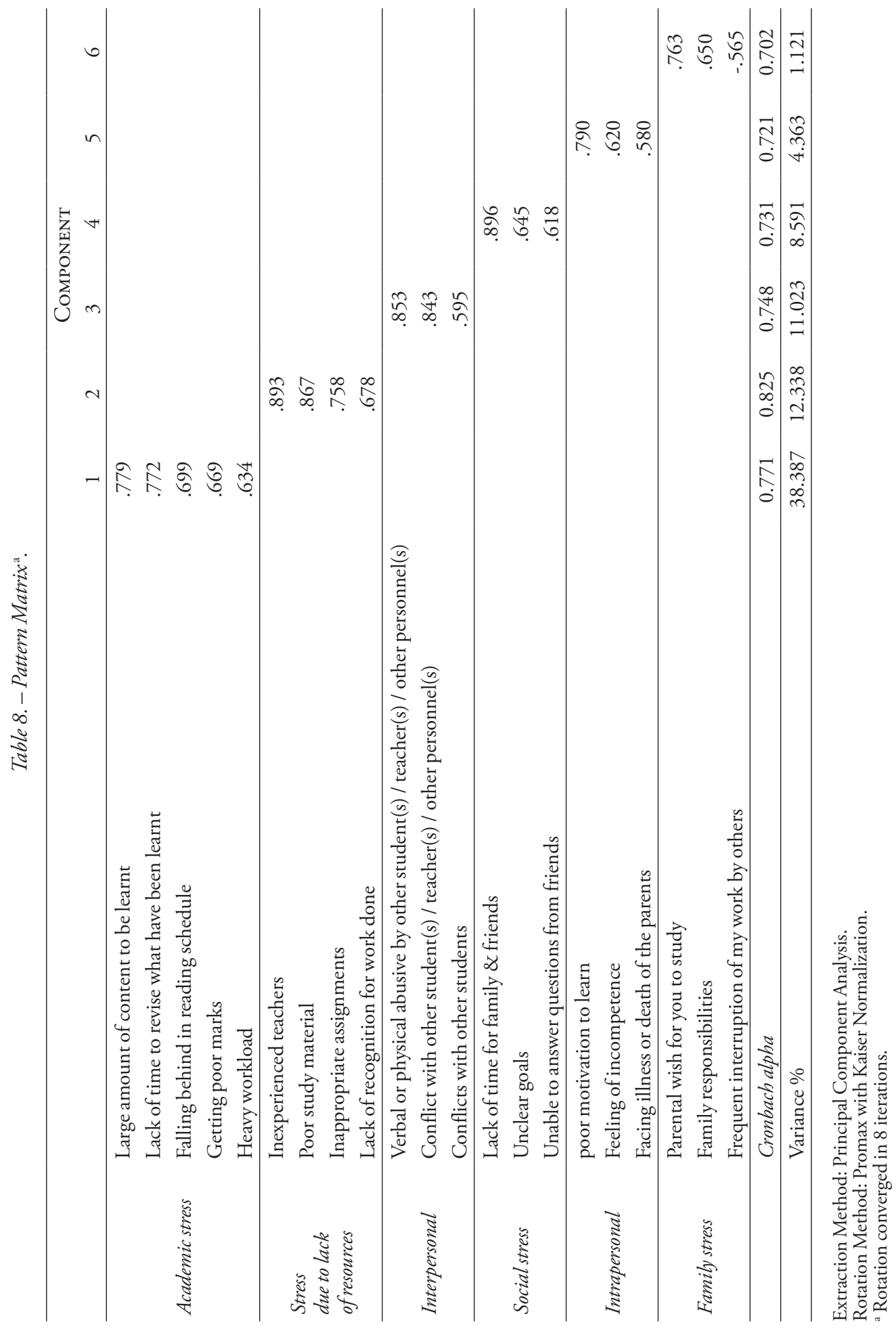


After extracting the above six factors reliability analysis was carried out to measure the reliability of the factor determining stress levels of students. Cronbach's alpha is the most commonly used measure of scale reliability, Cronbach (1951) suggests that alpha should be applied separately to each subscale when several factors exist. The internal consistency reliability estimates (Cronbach's alpha) for each stress level dimension ranged from 0.7 to 0.8 confirmed a satisfactory level of construct reliability (Kline, 1999).

\section{IMPLICATIONS FOR EDUCATORS AND POLICY MAKERS}

Our research study found out that among five personality traits, neuroticism is highly correlated with the student stressor, openness to experience is highly correlated with CGPA (academic performance). In the academic perspective, Neuroticism is a personality trait which tends to have a depressed feeling, easily disturbed mindset and frequent mood changes. Todays context, students studying in educational institutions possess this nature and they are easily becoming to the depressed state, for instance, when they get low marks or if they get caught when they go wrong.

Our findings are supported by the previous research by Clark and Schroth (2010) and Komaraju et al. (2009). First of all, the teachers should understand the heterogenous nature, the student possesses in terms of their unique personality. Most students in India score high on agreeableness and conscientiousness and low with regard to openness to experience and neuroticism. It should be noted that the correlation relationship with the two personality traits, namely conscientiousness and openness to experience are highly correlated with each other. Teachers should understand the difference in personality traits and adopt suitable teaching methodologies in handling the students. Second, students who are highly neurotic tends to exhibit low academic performance in terms of low CGPA. Hence the student's neurotic feel should be changed by conducting engagement activities and using proper channel to change their depressed mindset. A study by Walsh (2010) supported that the skill based and competency based training programs should be conducted for school program coordinators to educate the emotionally disturbed teenager. Nowadays, emotional intelligence is gaining more importance especially in the field of educational research to know more about the role of emotional intelligence and its relationship with the academic performance among students.

Third among academic stressor, large amount of content to be learnt, heavy workload, lack of time to revise were the reasons given by students. To 
provide a solution for this, employing thought-provoking course materials and reasonable workload will enhance the students to relieve out of academic stress to a greater extent. Considering inter and intra personal stress, verbal and physical abuse are creating more stress on students. This type of stress can be reduced by promoting a harmony among students through some group based activities. Social stress was created when they were highly involved in working with computers and frequent interruption by others when they are at work. These can be solved by making them actively involved in academics and nurturing them to be cooperative and peer learning strategies among the students. "Lack of time for family and friends» was accounted more for causing stress and to solve this issue, the management (university/college) should conduct talks on some management topics especially time management, stress handling mechanisms and motivation periodically (Sirca \& Sulcic, 2005).

At the ouset, our findings are more valuable for the teachers in India. The Indian education system is undergoing phenomenal changes and India is becoming an education super power by rich number of intellectual capital and strong value system. The students or the young talents, who are the backbone of the country's economic growth are given prime importance by the teacher. They should transform the very old traditional way of teaching which uses only the theoretical textbooks, instead they should employ teaching through case-studies, synthesis-analysis and elaborative-teaching methods. These contemporary approaches will enrich the students' metacognitive thinking, critical reasoning thereby reducing the unwanted stress created among students. Thus the study findings have practical implications for researchers as well as administrators of education sector, training organization and students. It provides decision makers with valuable insights in identifying factors of stress, personality of the students and helped to focus on order to improvement of student performance overall. Obviously, supportive, educational, administrative practices will greatly improve the academic performance of the students and their future placements.

\section{CONCLUSION}

The determination of personality factors and their impact on students is very important in the education system. Improving the academic performance quality, excellence and superiority of the student - Generation Y, who are the future employees of organization is vital in the current economical inclination. In this study multiple regression analysis has been used to measure the relationship between personality and stress level of student fraternity. In 
this research, an Exploratory Factor Analysis (EFA) was adapted in order to extract the underlying factors, namely (i) Academic stress; (ii) Stress due to lack of resources; (iii) Interpersonal stress; (iv) Social stress; (v) Intrapersonal stress and (vi) Family stress in determining the student stress. The personalities of the students were strongly related to stress level of the students which has a greater impact towards academic performance.

Based on the correlation results, it is interesting to conclude that neuroticism was highly correlated with the three types of stressors which means that persons who are emotionally unstable will be highly prone to stress. Based on the correlation relationship between conscientiousness and openness to experience it is understood that persons who are orderly and selfcontrolled tend to be more creative and innovative. The relationship between five personality traits and the academic performance (CGPA) was assessed and it is concluded that neuroticism was highly negatively correlated with one another which means that persons cannot do their best in their academics when they are emotionally unstable.

The student with the personality dimension of neuroticism (who is a anxious, moody and temperamental) has a strong relationship towards academic stressor $(\beta=0.715 ; p<0.000)$ and social related stressor $(\beta=0.384 ; p<$ $0.000)$. It is interesting to conclude that student with a personality dimension of openness to experience (who is curious, creative and intellectual) also has a strong relationship towards academic stressor $(\beta=0.696 ; p<0.000)$ and social related stressor $(\beta=0.442 ; p<0.000)$. Through factor analysis it can be concluded that $74.6 \%$ of the variance for «Lack of time for family $\&$ friends» is accounted for causing stress followed by $74.2 \%$ of the variance for «Inappropriate assignments» while $71.5 \%$ of the variance in «Verbal or physical abusive by other student(s) / teacher(s) / other personnel(s)» is accounted for stressors which affects the student performance.

The importance of these underlying dimensions of student stress has been studied thoroughly by various researchers (Clark et al., 1986; Yusoff et al., 2010; Saipanish, 2013).

\section{RESEARCH LIMITATIONS}

The information collected for the current research was cross-sectional data. To further explore, this study can be done at different stages in the student's academic careers and with the other constructs such as emotional intelligence, positive psychological capital etc. To generalize the above results, further research can be done with enlarged samples. 


\section{REFERENCES}

Aldwin, C., \& Greenberger, E. (1987). Cultural differences in the predictors of depression. American Journal of Community Psychology, 15(6), 789-813.

Blumberg, P., \& Flaherty, J. A. (1985). The influence of non-cognitive variables on student performance. Journal of Medical Education, 60(9), 721-723.

Carrus, G., Passiatore, Y., Pirchio, S., Passiatore, Y., Mastandrea, S., Scopelliti, M., $\&$ Bartoli, G. (2012). Contact with nature and children's wellbeing in educational settings. Journal of Social Sciences, 8(3), 304-309.

Clark, E. J., \& Rieker, P. P. (1986). Gender differences in relationships and stress of medical and law students. Journal of Medical Education, 61(1), 32-40.

Clark, M., \& Schroth, C. (2010). Examining relationships between academic motivation and personality among college students, Learning and Individual Differences, 20(1), 19-24.

Campbell, R. L., \& Svenson, L. W. (1992). Perceived level of stress among university undergraduate students in Edmonton, Canada. Perceptual and Motor Skills, 75(2), 552-554.

Cronbach, L. J. (1951). Coefficient alpha and the internal structure of tests. Psychometrika, 16, 297-334.

Donnellen, M. B., Oswald, F. L., Baird, B. M., \& Lucas, R. E. (2006). The miniIPIP Scales: Tiny-yet-effective measures of the Big Five factors of personality. Psychological Assessment, 18(2), 192-203.

D’Zurilla, T. J., \& Sheedy, C. F. (1991). Relation between social problem-solving ability and subsequent level of psychological stress in college students. Journal of Personality and Social Psychology, 61(5), 841-846.

Evans, E. J., \& Fitzgibbon, G. H. (1992). The dissecting room: Reactions of first year medical students. Clinical Anatomy, 5(4), 311-320.

Feng, G. F. (1992). Management of stress and loss. Taipei: Psychological Publishing Co., Ltd.

Field, A. P. (2005). Discovering statistics using SPSS (2nd ed.). London: Sage.

Fisher, S. (1994). Stress in academic life. Buckingham: Open University Press.

Greenberg, J. (1981). A study of stressors in the college student population. Health Education, 12(4), 8-12.

Hammer, L. B., Grigsby, T. D., \& Woods, S. P. (1998). The conflicting demands of work, family, and school among students at an urban university. The Journal of Psychology, 132(2), 220-226.

Kaiser, H. F. (1974). An index of factorial simplicity. Psychometrika, 39, 31-36.

Komarraju, M., \& Karau, S. J. (2005). The relationship between the Big Five personality traits and academic motivation. Personality and Individual Differences, 39, 557-567. 
Komarraju, M., Karau, S. J., \& Schmeck, R. (2009). Role of the Big Five personality traits in predicting college students' academic motivation and achievement. Learning and Individual Differences, 19(1), 47-52.

Kuncel, N. R., Crede, M., \& Thomas, L. L. (2005). The validity of self-reported grade point averages, class ranks, and test scores: A meta-analysis and review of the literature. Review of Educational Research, 75(1), 63-82.

Lazarus, R. S. (1991). Emotion and adaptation. Oxford: Oxford University Press.

Lazarus, R. S., \& Folkman, S. (1984). Stress, appraisal, and coping. New York: Springer.

O'Connor, M. C., \& Paunonen, S. V. (2007). Big Five personality predictors of post-secondary academic performance. Personality and Individual Differences, 43, 971-990.

Pancer, S. M., Hunsberger, B., Pratt, M. W., \& Alisat, S. (2000). Cognitive complexity of expectations and adjustment to university in the first year. Journal of Adolescent Research, 15, 38-57.

Pope, P. (1982). The relationship of selected intrapersonal, interpersonal, and life management skills to academic achievement among secondary school students. Dissertation, East Texas State University, Commerce, TX.

Rafidah, K., Azizah, A., Norzaidi, M. D., Chong, S. C., Salwani, M. I., \& Noraini, I. (2009). The impact of perceived stress and stress factors on academic performance of pre-diploma science students: A malaysian study. International Journal of Scientific Research in Education, 2(1), 13-26.

Saipanish, R. (2003). Stress among medical students in a Thai medical school. Medical Teacher, 25(5), 502-506.

Schafer, W. (1996). Passing the test of college stress. In W. Schafer (Ed.), Stress management for wellness (pp. 543-563). Orlando, FL: Harcourt Brace.

Sharma, N., \& Kaur, A. (2011). Factors associated with stress among nursing students. Nursing and Midwifery Research Journal, 7(1).

Sirca, N. T., \& Sulcic, V. (2005). Lifelong learning: Case study in higher education in Slovenia. International Journal Innovation and Learning, 2(2), 142-151.

Stevenson, A., \& Harper, S. (2006). Workplace stress and the student learning experience, Quality Assurance in Education, 14(2), 167-178.

Therasa, C., \& Vijayabanu, C. (2015). The impact of Big Five personality traits and positive psychological strengths towards job satisfaction: A review. Periodica Polytechnica - Social and Management Sciences, 23(2), 142-150.

Thurber, C. A., \& Walton, E. A. (2012). Homesickness and adjustment in university students. Journal of American College Health, 60(5), 415-419. doi: 10.1080/07448481.2012.673520

Towbes, L. C., \& Cohen, L. H. (1996). Chronic stress in the lives of college students: Scale development and prospective prediction of distress. Journal of Youth and Adolescence, 25, 199-217. 
Walsh, M. P. (2010). Employers' perceptions of transition programming for students with emotional disturbances. Journal of Employment Counselling, 47(3), 123 133.

Wright, J. J. (1967). Reported personal stress sources and adjustment of entering freshmen. Journal of Counseling Psychology, 14(4), 371-373.

Yusoff, M. S. B. (2011). A confirmatory Factor Analysis study on the Medical Student Stressor Questionnaire among Malaysian medical students. Education in Medicine Journal, 3(1), e44-e53. http://dx.doi.org/10.5959/eimj.3.1.2011.or5

Yusoff, M. S. B., Rahim, A. F. A., \& Yaacob, M. J. (2010). Prevalence and sources of stress among university Sains Malaysia medical students. Malaysia Journal of Mredical Science, 17(1).

\section{RiassunTO}

Il presente studio ha esplorato la relazione tra $i$ cosiddetti cinque grandi fattori di personalità e vari fattori di stress negli studenti universitari, laureati e dottandi di ricerca provenienti da nove università in Nord Chennai (India). Lo studio si basa su dati quantitativi con un disegno di ricerca descrittiva. Il questionario di personalità utilizzato comprende 20-item ed è stato sviluppato da Donnellen et al. (2006); i fattori di stress sono stati misurati usando la scala MSSQ (Medical Student Stressor Questionnaire) sviluppata da Yusoff (2011). Un totale di 250 studenti sono stati selezionati come partecipanti utilizzando una tecnica di campionamento casuale. Ė emersa una relazione positiva significativa tra il livello di nevroticismo e tre tipi di stress (accademico, inter-o intra-personale e sociale). Il tratto di personalità indicato come "apertura all'esperienza» sembra svolgere un ruolo importante nel predire il rendimento scolastico (CGPA). Attraverso il calcolo della regressione, si è rilevato inoltre un rapporto positivo significativo tra personalità e fattori di stress accademico e sociale. I risultati forniscono opportune indicazioni per gli educatori evidenziando l'importanza sia della personalità sia dell'applicazione di strategie idonee per migliorare il rendimento scolastico. La diffusione di tali risultati potrà contribuire in modo significativo ad aiutare gli studenti e gli educatori.

Parole chiave: Analisi fattoriale, Big Five, Regressione, Rendimento scolastico, Stress, Studente.

How to cite this Paper: Therasa, C., \& Vijayabanu, C. (2016). A dispositional approach to examine the impact towards students stressors in Indian context [Un approccio disposizionale per esaminare l'impatto degli studenti verso lo stress nel contesto indiano]. Journal of Educational, Cultural and Psychological Studies, 14, 35-56. doi: 10.7358/ecps-2016-014-thera 